\title{
Germination of Pollen Grains of Spathodia companulata P. Beauv in in vitro and in vivo like Condition with the Influence of a Promoter Medium
}

\author{
Pooja Sahu*, Pradnya Anasane, Alka Chaturvedi \\ PG Department of Botany, Rashtrasant tukadoji Maharaj Nagpur University, Nagpur, India
}

Received June 13, 2020; Revised October 23, 2020; Accepted December 3, 2020

\section{Cite This Paper in the following Citation Styles}

(a): [1] Pooja Sahu, Pradnya Anasane, Alka Chaturvedi, "Germination of Pollen Grains of Spathodia companulata P. Beauv in in vitro and in vivo like Condition with the Influence of a Promoter Medium, "Advances in Zoology and Botany, Vol. 9, No. 1, pp. 16 - 19, 2021. DOI: 10.13189/azb.2021.090103.

(b): Pooja Sahu, Pradnya Anasane, Alka Chaturvedi (2021). Germination of Pollen Grains of Spathodia companulata P. Beauv in in vitro and in vivo like Condition with the Influence of a Promoter Medium. Advances in Zoology and Botany, 9(1), 16 - 19. DOI: 10.13189/azb.2021.090103.

Copyright $\bigcirc 2021$ by authors, all rights reserved. Authors agree that this article remains permanently open access under the terms of the Creative Commons Attribution License 4.0 International License

\begin{abstract}
In vitro, germination is the most commonly used technique in pollen physiology. This provides a simple experiment method to study the pollen germination and pollen tube growth, in the endogenous as well as exogenous conditions. In vivo conditions (endogenous) can also apply to the study of pollen system. In the present investigation, the pollen germination of Spathodia companulata $\mathrm{P}$. Beauv was studied in the different parts of the carpel viz., style, stigma, ovary, style-stigma, style-ovary and whole gynoecium. Spathodia companulata P. Beauv is planted for reforestation schemes, for soil conservation. In India, it is seen that there is a rare formation of fruit and seeds in this plant. Thus for the study of the growth of the plant for cultivation purposes, the growth of the pollen tube was studied which could be one of the reason for the less fruit and seed formation. Pollen tubes were found to be stimulated by those components present in the different selected parts of the carpel.
\end{abstract}

Keywords In vitro, in vivo like Condition, Pollen Germination, Pollen System Female Reproductive Parts (FRP)

\section{Introduction}

Spathodea campanulata is an African plant introduced into South America and other tropical and subtropical areas for ornamental purposes. The flowers bloom with great profusion, and the trees can be seen from great distances. It is not browsed by domestic animals and although a popular decorative tree for avenues. It has shallow roots and a tendency for branches to break off in a storm. The unopened flower buds contain a sweet, watery liquid that is considered to be tonic [1]. The seeds, flowers and roots are used as medicine in most of the African countries. The tree is planted for soil improvement, reforestation, erosion control and land rehabilitation.

Before attempting any breeding experiment, testing the germinability of pollen from different sources is necessary. Methods for testing pollen grain viability usually employ either the flurochromatic reaction test or germinability test under near optimum germination conditions. In vitro pollen germination studies not only help in understanding different aspects of pollen biology but are also crucial for assisted breeding programmes, in which regular monitoring of germinability of pollen samples that are stored, is required [2]. BK (Brewbacker and Kwack) medium is the most frequently used and has been found to be suitable for over number plant species. However, flowering plant species do not always respond satisfactorily to BK medium and thus adjustment in the concentration of the medium component is required sometimes [3]. Therefore, pollen germination media recommended so far range from simple sugar/boric acid 
media [4] to complex ones containing polyethylene glycol (PEG) formulated by Zhang and Croes (1982) and Tandon et al. (1999) [5, 6].

The aim of this study provides the details of formulation of an optimized pollen germination medium as an in vitro study with the association of the conditions of in vivo provided to study by observing the effect of different parts of carpels on the pollen tube growth in Spathodea companulata.

\section{Materials and Method}

\subsection{Collection of Plant Material}

The present study was conducted on $S$. companulata $P$. Beauv collected from RTMNU, Nagpur, Campus premises (Figure 1). The identification was confirmed by the flora of Maharashtra Vol. I and II [7].

\section{Classification}

Kingdom: Plantae

Subkingdom: Tracheobionta

Superdivision: Spermatophyta

Division: Magnoliophyta

Class: Magnoliopsida

Subclass: Asterideae

Family: Bignoniaceae

Genus: Spathodia

Species: companulata

P. Beauv

\subsection{In vitro and in vivo like Conditions for Pollen Germination and Tube Growth}

To standardize the germination medium, for pollen germination and pollen tube development, the different extracts of female reproductive part (gynoecium) viz., stigma, style, ovary, stigma-style, style-ovary and whole gynoecium were raised in various concentration of Brewbacker and Kwack (BK) medium (10\%, 20\% and $30 \%$ ) which contain Sucrose- 25\%, Boric acid: $0.01 \%$ $(10 \mathrm{mg} / 100 \mathrm{ml})$, Calcium nitrate: $0.03 \%(30 \mathrm{mg} / 100 \mathrm{ml})$, Magnesium sulphate: $0.02 \%(20 \mathrm{mg} / 100 \mathrm{ml})$, Potasium nitrate: $0.01 \%(10 \mathrm{mg} / 100 \mathrm{ml})$. Pollen grains were dusted in each grade of BK medium and incubated at room temperature for 1- 4 hours. After incubation one drop of this solution was placed on a clean glass slide and it was stained with $1 \%$ aceto-orcein and glass cover was placed over it. It was then observed after few minutes under microscope. Pollen germination percentage and tube growth were evaluated. The germination response of pollen was expressed as percentage. The length of pollen tube was measured using a calibrated ocular micrometer.

\section{Results}

The percentage of pollen germination and pollen tube growth was assessed in the extract of different Female Reproductive parts (FRP) respectively. An attempt made to test the effect of various concentrations of FRP extract was able to enhance the germination response and showed highest pollen tube length. Initially no germination response was achieved up to $30 \mathrm{~min}$ of incubation in BK medium supplemented with the extract of all female reproductive parts (FRP). However, the pollen grains responded to germination after the incubation period was extended up to $1-4$ hours at room temperature with the same composition. Ovary extract gave the best response to germination while maximum tube growth was noticed in the extract of whole gynoecium (Table 1 and Figure 2, 3). This shows that pollen germination and tube growth regulated by all the components present in the whole gynoecium. Overall $20 \%$ and $30 \%$ BK concentration shows maximum germination in one and other selected parts of gynoecium.
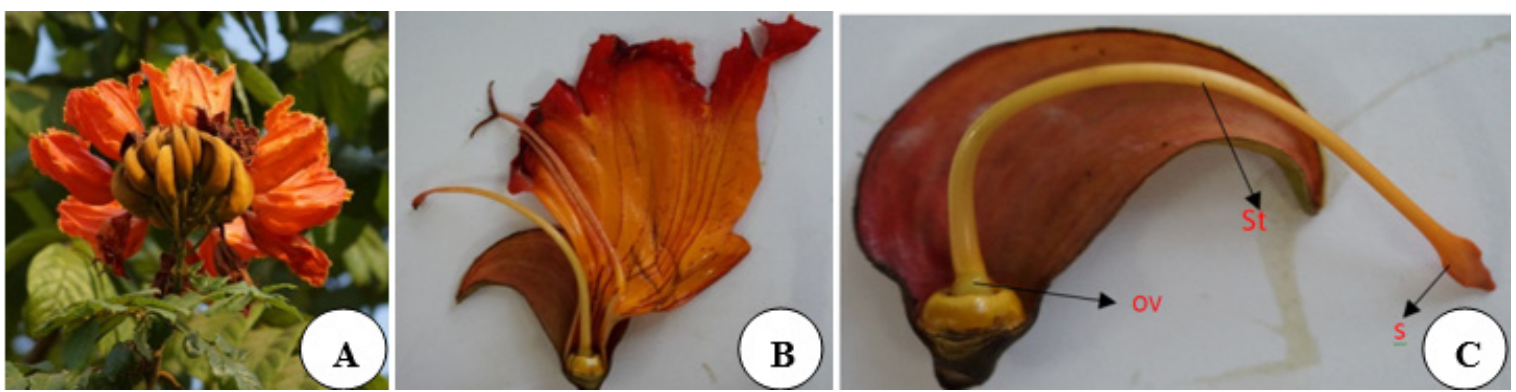

Figure 1. Spathodea companulata: A. Inflorescence with young buds and open flowers. B. Open flower showing anthers and stigma. C. Pistil with terminal style (St), bilobed and closed stigma (s) and the nectariferous disc at the base of ovary (ov) 
Table 1. Pollen Tube Length (in $\mu \mathrm{m}$ ) in Different Female Reproductive Parts

\begin{tabular}{|c|c|c|c|c|c|c|}
\hline & Style & Ovary & Stigma-Style & Style-Ovary & Whole Gynoecium & Stigma \\
\hline $10 \%$ & $17.73 \pm 3.37$ & $9.33 \pm 0.93$ & $20.53 \pm 0.93$ & $27.13 \pm 3.35$ & $60.67 \pm 5.19$ & $11.5 \pm 0.3$ \\
\hline $20 \%$ & $21.47 \pm 6.53$ & $7.47 \pm 0.93$ & $17.73 \pm 1.87$ & $38.27 \pm 6.73$ & $59.73 \pm 4.94$ & $12.61 \pm 0.67$ \\
\hline $30 \%$ & $26.13 \pm 6.12$ & $6.53 \pm 0.94$ & $16.8 \pm 1.61$ & $29.87 \pm 10.4$ & $56.93 \pm 6.12$ & $13.71 \pm 0.44$ \\
\hline
\end{tabular}

Values are Mean (Pollen tube Length in $\mu \mathrm{m}) \pm \operatorname{SEM}(\mathrm{n}=3)$

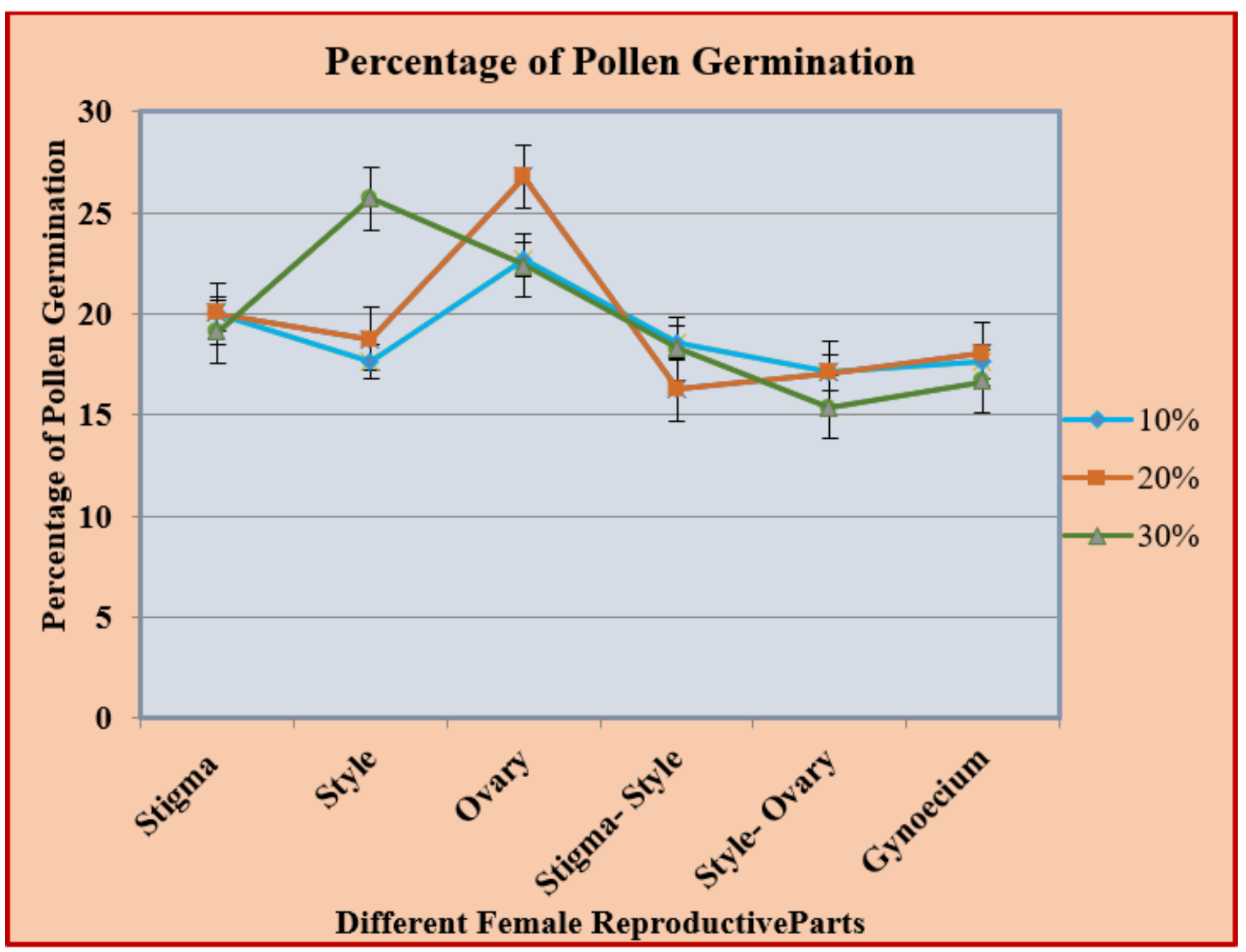

*Values are Mean $\pm \operatorname{SEM}(\mathrm{n}=3)$

Figure 2. Effect of Female Reproductive parts (FRP) on pollen germination
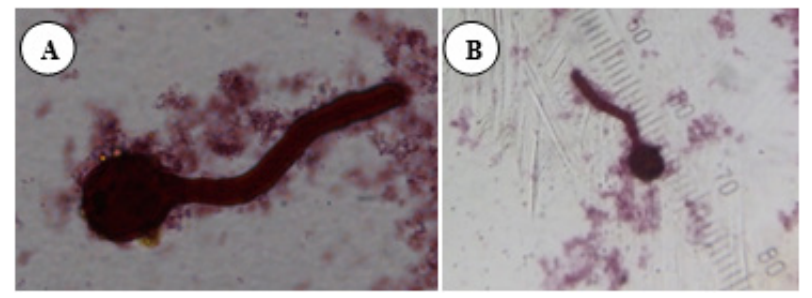

Figure 3. A-Germinated pollen grain in Gynoecium; B-Measurement of Pollen tube with ocular

\section{Discussion}

The pollen grains of Spathodea campanulata failed to respond well in vitro. Thus it became essential to optimize a germination medium suitable in in vivo for this species.

The sugar in the medium acts as an osmotic regulant which regulates the diffusion rate of water from the medium into pollen grains. The failure of pollen to germinate and its bursting may indicate lack of sugars within pollen grains and critical dependence on external supply [8]

Pollen grains are believed to be deficient in boron, which is normally compensated by high levels of boron present in stigma and style. Boron combines with sugar to form a sugar-borate complex which facilitates translocation of sugar molecules [9]. Its exogenous application, as observed in many trees, significantly influences both pollen germination and tube growth $[10$, $11,12]$. 
In both in vitro and in vivo conditions, optimal pollen germination and continued tube growth require a high level of calcium (Ca) (300-5000 ppm). Calcium is involved in cationic balance and is essential for tube elongation $[3,13,14]$.

In the present study a noteworthy increase in the germination rate of Spathodea campanulata pollen in Female Reproductive parts (FRP) extract supplemented medium indicated its positive influence. The pollen grains of Spathodea campanulata lack those substances (like Boron) which were endogenously present in the Female Reproductive part (FRP) of flower. Thus the application of the BK medium with the extract improved the response. Thus our study demonstrates that the pollen grains of Spathodea campanulata might be deficient in those mineral components which required for the pollen grain germination and tube growth. But under in vivo conditions the same nutrients are perhaps supplied by the stigmatic exudate for attaining successful fertilization and seed-set. Also BK medium increases the rate of pollen tube development giving in vitro condition.

\section{Conclusions}

The growth of pollen tube is stimulated by those components which are only present in the whole gynoecium. The pollen tube requires the natural substances for elongation and which are possibly present in in vivo condition but there are some limitations in the natural conditions causes less fruit and seed formation. BK medium as a promoter influence the growth of pollen tube more rapidly. Thus a simple medium may be developed to suit the germination requirement of pollen.

\section{Acknowledgements}

Author is thankful to the Head of the department allow me to work in the laboratory.

\section{REFERENCES}

[1] Facciola, S. The second edition of an excellent guide to the edible uses of plants. Kampang Publications, California. ISBN 0-9628087-2-5, 1988.

[2] Heslop, J. Harrison. Pollen germination and pollen-tube growth. Int. Rev. Cytol. 107 1-78, 1987.

[3] Brewbaker, J. L., Kwack, B.H. The calcium ion and substances influencing pollen tube growth. In: Linskens (ed.) Pollen physiology and fertilization. Elsevier North Holland, Amsterdam. 145-151,1964.

[4] Stanley, R.G., Linskens, H.F. Enzyme activation in Petunia pollen. Nature 203: 542-544, 1964.

[5] Zhang, H.Q., Croes, A. F. A new medium for pollen germination in vitro. Acta. Bot. Neerl. 31(1-2) 113-119, 1982.

[6] Tandon, R., Manohara, T. N., Nijalingappa, B. H. M. and Shivanna, K. R. Polyethylene glycol enhances in vitro 'germination and tube growth of oil palm pollen. Exp. Biol. 37(2) 169-172, 1999.

[7] Singh, N., Kartikeyan, S. Flora of Maharashtra state, Botanical Survey of India, 2000.

[8] Johri, B. M., Vasil, I. K. Physiology of pollen. The Botanical Review.;27:325-381, 1961.

[9] Vasil, K. Effect of boron on pollen germination and pollen growth. In: Linskens JF, editor. Pollen Physiology and Fertilization. Amsterdam, The Netherlands: North Holland Publishing Co.; 1963

Montaner, C., Floris, E. and Alvarez, J. M. Study of pollen cytology and evaluation of pollen viability using in vivo and in vitro test, in borage (Borago officinalis L.). Grana 42 (1) 33-37,2003.

[10] Lewis, D. H. Boron lignification and the origin of vascular plants. A unified hypothesis. New Phytol. 84 (2) 209-229, 1980.

[11] Wang, Q., Lu,. L, Wu,. X, Li,. Y and Lin, J. Boron influences pollen germination and pollen tube growth in Picea meyeri. Tree Physio. 23 (5) 345-351, 2003.

[12] Wojcik, P. and Wojcik, M. Effects of boron fertilization on 'Conference' pear tree vigour, nutrition and fruit yield and storability. Plant soil 256: 413-421, 2003.

[13] Todd, F.E., Bretherick, O. The composition of pollens. medium for pollen J. Econ. Entomol. 35: 312-317, 1942. 